\title{
Crescimento vegetativo de porta-enxertos de citros produzidos em substratos comerciais
}

\author{
Vegetative growth of citrus rootstocks producing in distinct commercials substrates
}

\author{
Mário Luís Fochesato ${ }^{\mathrm{I}}$ Paulo Vitor Dutra de Souza' ${ }^{\mathrm{I}}$ Gilmar Schäfer ${ }^{\mathrm{I}}$ \\ Hardi Schmatz Maciel ${ }^{\mathrm{I}}$
}

\section{RESUMO}

Este trabalho teve o objetivo de avaliar o crescimento vegetativo de porta-enxertos de citros produzidos em diferentes substratos comerciais, mantidos em recipientes de quatro litros. $O$ experimento foi desenvolvido em casa de vegetação, na Estação Experimental Agronômica da UFRGS, em Eldorado do Sul, RS, no período de junho/2003 a março/ 2004, e seguiu o delineamento experimental de blocos casualizados, testando-se três substratos comerciais: Turfa preta (Comercial 1); cascas processadas e enriquecidas, vermiculita expandida, perlita expandida e turfa (Comercial 2); e casca de pínus compostada e vermiculita (Comercial 3) e três portaenxertos: ("Trifoliata”; citrangeiro "C13” e limoeiro "Cravo"). A irrigação foi feita por gotejamento. Avaliaram-se as seguintes variáveis: diâmetro do colo; altura da parte aérea; número de folhas e área foliar; matéria seca das raízes, da parte aérea e total; conteúdo de nutrientes nas folhas e percentual de portaenxertos aptos à enxertia. A interpretação dos resultados revelou que o substrato com cascas processadas e enriquecidas, vermiculita expandida, perlita expandida e turfa possibilitou maior desenvolvimento vegetativo aos porta-enxertos utilizados, devido ao maior aporte de nutrientes. Os portaenxertos mostraram desenvolvimento diferenciado, sendo que o citrangeiro " $\mathrm{C} 13$ ” tem potencial de uso para a diversificação de porta-enxertos na citricultura, devido ao seu desenvolvimento vegetativo.

Palavras-chave: ambiente protegido, meios de cultivo, Citrus sp., variedades.

\section{ABSTRACT}

This research was aimed at evaluating the vegetative growth of citrus rootstocks produced in different commercial substrates and cultivated in four liters containers. The experiment was carried out in greenhouse conditions at the Estação Experimental Agronômica of the Universidade Federal do Rio
Grande do Sul, from June 2003 to July 2004. Three commercial substrates [black peat (Commercial 1); processed and enriched husks, expanded vermiculite, expanded perlite and peat (Commercial 2); and (pinus husks and expanded vermiculite (Commercial 3)] and three rootstocks (Trifoliate orange Poncirus trifoliata [ L. ] Raf.; "C13” citrange - Citrus sinensis [ L. ] Osbeck x P. trifoliata, and Rangpur lime - C. limonia Osbeck) were tested in randomized blocks under dripping irrigation. The following variables were evaluated: stem height and diameter; leaf number and area; root, aerial and total dry mass; leaf nutrient content and relative number of available rootstocks for grafting. The substrate with processed and enriched husks, expanded vermiculite, expanded perlite and peat provided greater vegetative development of rootstocks due to higher nutrient availability. The rootstocks showed diverse development. The "C13" citrange may be offered to the citrus industry as a choice for diversification of rootstocks, due its vegetative growth.

Key words: greenhouse, cultivation, Citrus sp., varieties.

\section{INTRODUÇÃO}

O cultivo de mudas cítricas em ambiente protegido favorece a produção de plantas de elevada qualidade genética e sanitária. Este cultivo necessita ser feito em recipientes, onde as mudas produzidas alteram seu desenvolvimento em função do meio de cultivo, quando comparado com o processo a campo, com a limitação do espaço para o crescimento das raízes. Deste modo, o substrato deve possibilitar o perfeito desenvolvimento das raízes. Para isso, é necessário conhecer a qualidade do mesmo, através de suas características químicas e físicas, onde as mais

I Departamento de Horticultura e Silvicultura, Faculdade de Agronomia, Universidade Federal do Rio Grande do Sul (UFRGS). Av. Bento Gonçalves 7712, CP 15100, 91501-970, Porto Alegre, RS, Brasil. E-mail: pvdsouza@ufrgs.br. 
importantes são o valor do $\mathrm{pH}$, a capacidade de troca de cátions, a condutividade elétrica e/ou teor total de sais solúveis; a densidade de volume, a porosidade total, o espaço de aeração e a retenção de água a baixas tensões de umidade (FERMINO, 1996). Em decorrência das características dos substratos e das restritas condições dos recipientes, os porta-enxertos respondem com diferentes níveis de crescimento, que vão influenciar no tempo de obtenção da muda.

Os porta-enxertos podem afetar a qualidade e a produtividade dos frutos, bem como a resistência, a tolerância e a suscetibilidade aos patógenos e pragas, e são afetados pelo tipo de solo e pelas condições climáticas (LEITE JUNIOR, 1992). Na Região Sudeste, $71 \%$ das plantas cítricas estão enxertadas sobre o portaenxerto limoeiro "Cravo", que permite obter maior precocidade, com alta produção e boa resistência à seca. A partir de 2001, esse porta-enxerto mostrou-se suscetível à morte súbita, trazendo sérios prejuízos (FUNDECITRUS, 2004). Segundo SCHÄFER (2000), no Rio Grande do Sul, cerca de $90 \%$ das plantas estão enxertadas sobre o Poncirus trifoliata, que é resistente às baixas temperaturas, à gomose e induz a produção de frutos com excelente qualidade. Conseqüentemente, apesar das boas qualidades desses porta-enxertos, a falta de diversificação nas regiões de cultivo pode causar sérios prejuízos à citricultura, no caso da entrada de novas doenças (KOLLER, 1994; SCHMITZ, 1998). Portanto, o teste de outras cultivares de porta-enxertos, como os citranges (Citrus sinensis [L.] Osbeck $\mathrm{x}$ Poncirus trifoliata [L.] Raf.), pode servir como alternativa de diversificação e segurança para a citricultura gaúcha e brasileira.

O presente estudo tem como objetivo avaliar o crescimento vegetativo de distintas variedades de porta-enxertos de citros produzidos em diferentes substratos comerciais.

\section{MATERIAL E MÉTODOS}

O experimento foi realizado em casa de vegetação na Estação Experimental Agronômica da Universidade Federal do Rio Grande do Sul (EEA/ UFRGS), em Eldorado do Sul - RS, no período de junho de 2003 a março de 2004. O mesmo compreendeu um período de 265 dias, a contar desde o momento da repicagem dos porta-enxertos dos tubetes de $50 \mathrm{~cm}^{3}$ para citropotes de quatro litros, até estes estarem aptos à enxertia.

O delineamento experimental adotado foi em blocos casualizados, em esquema fatorial, testando-se dois fatores, que foram: três substratos comerciais (Comercial 1, Comercial 2 e Comercial 3) e três variedades de porta-enxertos (“Trifoliata” - Poncirus trifoliata
[L.] Raf.; citrangeiro “C13”-Citrus sinensis [L.] Osbeck x P. trifoliata [L.] Raf.; e limoeiro "Cravo" - C. limonia Osbeck). O experimento foi executado em 3 blocos, com 9 tratamentos e 4 plantas por parcela.

Os substratos comerciais apresentavam as seguintes composições: composto de turfa preta (Comercial 1), composto de cascas processadas e enriquecidas, vermiculita expandida, perlita expandida e turfa(Comercial 2) e composto de casca de pínus compostada e vermiculita (Comercial 3).

Os porta-enxertos utilizados neste estudo são provenientes de casa de vegetação, produzidos em tubetes cônicos (tamanho 3 x 12cm - volume de $50 \mathrm{~cm}^{3}$ ). Os mesmos foram padronizados pela altura, em torno de $10 \mathrm{~cm}$, e pelo desenvolvimento radicular completo, e repicados para os citropotes (tamanho $15 \mathrm{~cm}$ x $35 \mathrm{~cm}$ - volume de $4000 \mathrm{~cm}^{3}$ ), com substratos comerciais.

A irrigação foi feita mediante gotejamento, em torno de duas a três vezes ao dia, com duração de cinco a dez minutos cada. Os maiores períodos foram utilizados em condições de alta temperatura (verão) e os menores períodos em baixa temperatura (inverno). A fertilização foi efetuada via água de irrigação, com uma solução nutritiva elaborada na EEA/UFRGS, numa concentração de 400ppm, a cada 24 horas. A solução nutritiva apresentava a seguinte composição: N (5,5\%), P (1,05\%), K (5,20\%), Ca (3\%), Mg (1\%), S (0,1\%), Fe (0,017\%), Zn (0,018\%), Mn (0,01\%), B (0,01\%), Cu $(0,003 \%)$ e $\operatorname{Mo}(0,004 \%)$.

Após 265 dias, foram avaliados os seguintes parâmetros: número de folhas por planta; área foliar por planta, medida através da passagem das folhas por um medidor de área foliar de marca LI-Cor, modelo LI 3100, em cm²; área foliar por folha, obtida pela divisão da área foliar pelo número de folhas por planta, em $\mathrm{cm}^{2}$; altura da parte aérea, medida do colo até o ápice, em cm; diâmetro do caule, ao nível do colo, em mm; matéria seca da raiz, parte aérea e total (raiz + parte aérea), em gramas, obtidas pela secagem em estufa, com temperatura de $65^{\circ} \mathrm{C}$, até peso constante; conteúdo de nutrientes presentes na matéria seca das folhas, pela determinação de $\mathrm{N}$ (total), P, K, Ca e Mg, segundo metodologia descrita por TEDESCO et al. (1995), e percentual de porta-enxertos aptos à enxertia. Neste caso, considerou-se apto à enxertia aquele portaenxerto que apresentava um diâmetro superior a 6,8 $\mathrm{mm}$ ao nível do colo, significando que, aos $10 \mathrm{~cm}$ acima do solo, possuía um diâmetro em torno de $5 \mathrm{~mm}$ (diâmetro mínimo para a enxertia).

As características químicas e físicas dos substratos ao longo do cultivo foram determinadas segundo métodos descritos por TEDESCO et al. (1995) e por BELLÉ \& KÄMPF (1994), e estão apresentadas na tabela 1. 
Tabela 1 - Características químicas e físicas dos substratos no momento da repicagem dos porta-enxertos e no momento da enxertia, em casa de vegetação. EEA/UFRGS, Eldorado do Sul, 2003/2004.

\begin{tabular}{|c|c|c|c|c|c|c|c|c|c|c|c|c|}
\hline \multirow{3}{*}{ Substratos } & \multirow{3}{*}{ Épocas } & \multicolumn{7}{|c|}{ Características químicas } & \multicolumn{4}{|c|}{ Características físicas } \\
\hline & & \multirow{2}{*}{$\mathrm{pH}$} & $\mathrm{TTSS}^{1}$ & $\mathrm{P}^{2}$ & $\mathrm{~K}^{3}$ & $\mathrm{Ca}^{4}$ & $\mathrm{Mg}^{5}$ & $\mathrm{CTC}^{6}$ & \multirow{2}{*}{$\mathrm{PT}^{7}$} & \multirow{2}{*}{$\mathrm{EA}^{8}$} & \multirow{2}{*}{$\mathrm{AD}^{9}$} & \multirow{2}{*}{$\mathrm{AR} 100^{10}$} \\
\hline & & & $\mathrm{G} \mathrm{L}^{-1}$ & \multicolumn{2}{|c|}{$\ldots . . m g \mathrm{~L}^{-1} \ldots .}$. & \multicolumn{3}{|c|}{$\ldots \ldots \ldots \mathrm{cmol}_{\mathrm{c}} \mathrm{L}^{-1} \ldots \ldots \ldots$} & & & & \\
\hline Comercial & Repicagem & 6,1 & 1,1 & 117,0 & 274,0 & 30,6 & 6,1 & 41,0 & 0,77 & 0,35 & 0,09 & 0,34 \\
\hline 1 & Enxertia & 7,0 & 0,2 & 9,4 & 28,9 & 21,1 & 4,7 & 25,8 & 0,83 & 0,31 & 0,12 & 0,39 \\
\hline Comercial & Repicagem & 5,4 & 2,2 & 350,0 & 742,0 & 25,0 & 9,5 & 40,3 & 0,82 & 0,31 & 0,17 & 0,34 \\
\hline 2 & Enxertia & 6,8 & 0,2 & 169,8 & 118,0 & 15,1 & 3,8 & 19,2 & 0,88 & 0,36 & 0,14 & 0,38 \\
\hline Comercial & Repicagem & 5,7 & 1,0 & 271,0 & 364,0 & 11,7 & 10,7 & 26,9 & 0,90 & 0,35 & 0,16 & 0,39 \\
\hline 3 & Enxertia & 7,2 & 0,2 & 63,9 & 36,9 & 11,8 & 4,9 & 16,8 & 0,95 & 0,39 & 0,16 & 0,40 \\
\hline
\end{tabular}

${ }^{1}$ Teor total de sais solúveis, ${ }^{2}$ Fósforo, ${ }^{3}$ Potássio, ${ }^{4}$ Cálcio trocável, ${ }^{5}$ Magnésio trocável, ${ }^{6}$ Capacidade de troca de cátions, ${ }^{7}$ Porosidade total, ${ }^{8}$ Espaço de aeração, ${ }^{9}$ Água disponível e ${ }^{10}$ Água remanescente ao potencial de -100hPa.

As temperaturas do ar dentro da casa de vegetação, obtidas através do Termohigrógrafo, modelo 3-3122, da marca ISUZU SEISAKUSHO CO. LTDA, e fora da casa de vegetação, obtidas em abrigo meteorológico (BERGAMASCHI, 2004), estão representadas na figura 1 .

A análise estatística compreendeu a análise de variância e as médias foram submetidas ao teste de Tukey em nível de 5\% de significância.

\section{RESULTADOS E DISCUSSÃO}

A área foliar, o número de folhas por planta e a área foliar por folha (Tabela 2) foram afetados pela interação entre os fatores substrato x porta-enxerto. A maior área foliar foi apresentada pelo porta-enxerto limoeiro "Cravo", seguido pelo citrangeiro “C13”, quando produzidos no substrato Comercial 2. Ao serem produzidos no substrato Comercial 1, os três porta- enxertos apresentaram área foliar semelhante entre si, enquanto que, se produzidos no substrato Comercial 3, o porta-enxerto citrangeiro "C13" e o limoeiro "Cravo" foram superiores ao "Trifoliata”. O porta-enxerto “Trifoliata” apresentou área foliar semelhante nos três substratos utilizados, enquanto que o limoeiro "Cravo" e o citrangeiro "C13" apresentaram maior área foliar quando produzidos no substrato Comercial 2.

No que tange ao número de folhas por planta (Tabela 2), os três porta-enxertos apresentaram número de folhas semelhantes quando produzidos nos substratos Comercial 1 e Comercial 3. Porém, quando produzidos no substrato Comercial 2, o porta-enxerto limoeiro "Cravo" apresentou maior número de folhas, seguido pelo porta-enxerto "Trifoliata” e, com menor número de folhas, pelo porta-enxerto citrangeiro “C13”. O "Trifoliata" manteve o mesmo tamanho de folhas nos três substratos, enquanto os porta-enxertos citrangeiro "C13” e limoeiro “Cravo" apresentaram

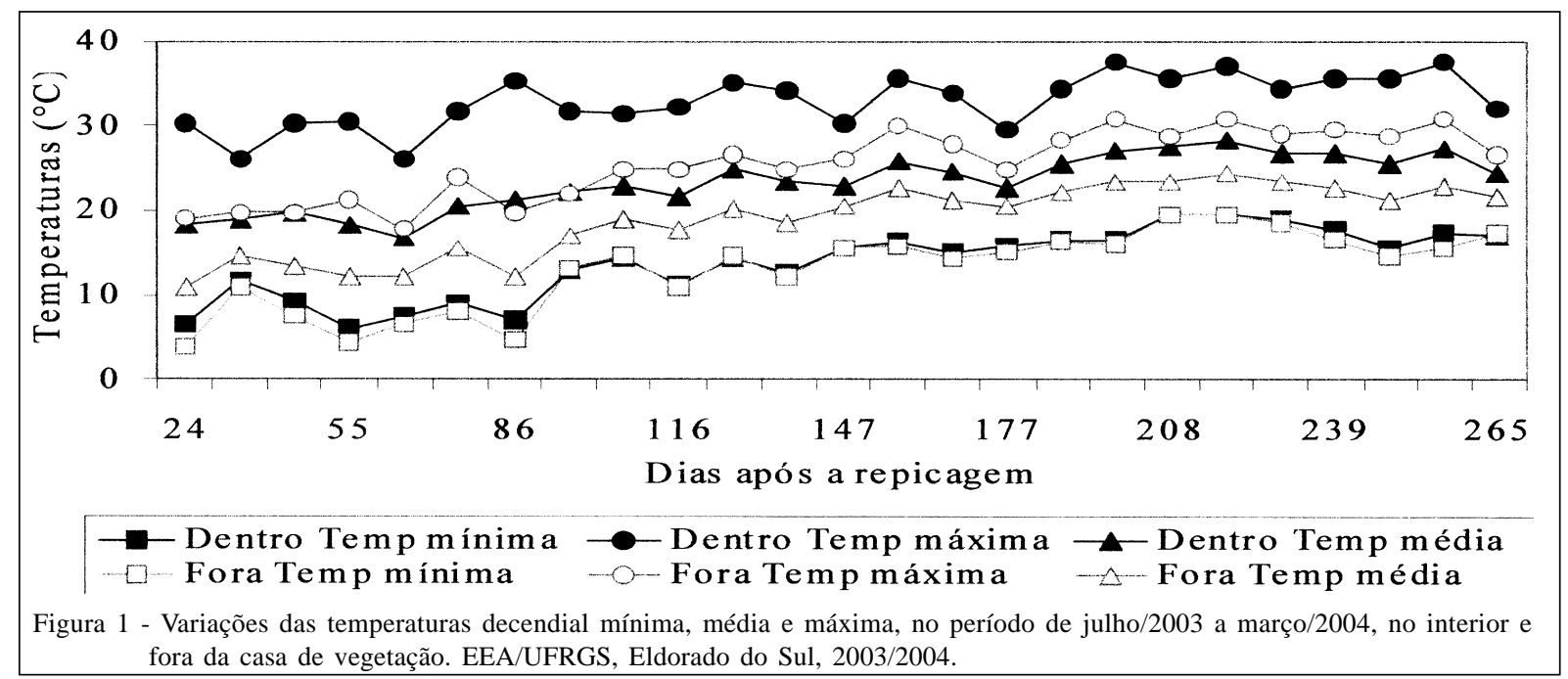

Ciência Rural, v.37, n.4, jul-ago, 2007. 
Tabela 2 - Área foliar e número de folhas por planta e área foliar por folha de porta-enxertos de citros, produzidos em recipientes com diferentes substratos em casa de vegetação. EEA/UFRGS, Eldorado do Sul, 2003/2004.

\begin{tabular}{|c|c|c|c|c|c|c|c|c|c|}
\hline \multirow{3}{*}{ Substratos } & \multicolumn{3}{|c|}{ Área foliar $\left(\mathrm{cm}^{2}\right.$ planta $\left.^{-1}\right)$} & \multicolumn{3}{|c|}{ Número de folhas planta ${ }^{-1}$} & \multicolumn{3}{|c|}{ Área foliar $\left(\mathrm{cm}^{2}\right.$ folha $\left.{ }^{-1}\right)$} \\
\hline & \multicolumn{3}{|c|}{ Porta-enxertos } & \multicolumn{3}{|c|}{ Porta-enxertos } & \multicolumn{3}{|c|}{ Porta-enxertos } \\
\hline & "Trifoliata" & “Cravo” & “C13” & "Trifoliata" & “Cravo” & “C13” & "Trifoliata" & “Cravo” & “C13” \\
\hline Comercial 1 & $44,60 \mathrm{Aa}^{1}$ & $207,06 \mathrm{Ab}$ & $240,92 \mathrm{Ab}$ & 35,92 Ab & 43,67 Ab & $32,58 \mathrm{Ab}$ & 1,22 Ba & 4,67 ABb & 7,34 Ab \\
\hline Comercial 2 & 204,40 Ca & 1015,60 Аа & 735,56 Ва & $74,00 \mathrm{Ba}$ & 98,00 Аа & 52,58 Ca & 2,71 Ba & 10,36 Аa & 13,70 Аа \\
\hline Comercial 3 & 52,86 Ba & 266,86 Ab & $361,49 \mathrm{Ab}$ & 38,08 Ab & $50,00 \mathrm{Ab}$ & $44,00 \mathrm{Ab}$ & 1,40 Ba & $5,28 \mathrm{ABb}$ & 8,15 Ab \\
\hline CV (\%) & 33,41 & & & 15,38 & & & 25,54 & & \\
\hline
\end{tabular}

${ }^{1}$ Médias não seguidas por mesma letra maiúsculas na linha e minúsculas na coluna diferem entre si pelo teste de Tukey a 5\% de probabilidade de erro.

maior área foliar por folha quando produzidos no substrato Comercial 2, não diferindo nos outros dois substratos.

Apesar do porta-enxerto “Trifoliata” apresentar um valor intermediário no número de folha por planta em relação aos demais, este resultou numa menor área foliar por folha, sendo conseqüência de suas características genotípicas. Também SCHÄFER (2004), testando diferentes substratos e porta-enxertos na fase de sementeira, verificou que os porta-enxertos “C13” e limoeiro "Cravo” apresentaram maior área foliar por folha do que o "Trifoliata”, que apresentou menor área foliar por folha. O referido autor obteve maior área foliar por folha quando utilizou o mesmo substrato Comercial 2 utilizado neste experimento.

A altura e o diâmetro revelaram diferenças com efeitos simples dos substratos e dos portaenxertos (Tabela 3). Nestas características, o substrato Comercial 2 induziu um maior desenvolvimento vegetativo das plantas, quando comparado aos outros substratos, os quais não diferiram entre si. Quanto aos porta-enxertos, o citrangeiro “ $\mathrm{C} 13$ ” apresentou maior altura e diâmetro em relação ao "Trifoliata” e ao limoeiro “Cravo”. Apesar de o "Trifoliata” apresentar uma maior altura que o limoeiro "Cravo”, não diferiu deste em relação ao diâmetro do colo, sendo que no sistema de produção de mudas é o parâmetro mais importante, já que determina o momento de realização da enxertia e a precocidade da muda produzida.

As plantas produzidas no substrato Comercial 2 sobressaíram-se em relação às demais com maior quantidade de matéria seca nas raízes e na parte aérea (Tabela 3). Este maior acúmulo de matéria seca nos porta-enxertos é explicado pelo maior aporte de nutrientes presente inicialmente no substrato Comercial 2, quando comparado com os outros dois substratos, aliado a variações físicas nos mesmos, pois o Comercial 1 apresentou menos água disponível e o Comercial 3 maior água remanescente, em relação ao Comercial 2. Isto deve ter dificultado a disponibilidade de água às plantas (Tabela 1). Deste modo, torna-se necessário um manejo diferenciado na irrigação para os substratos Comercial 1 e Comercial 3, aumentando o volume de água disponível às plantas, indicando um maior número

Tabela 3 - Altura, diâmetro e matéria seca da raiz, da parte aérea e total dos porta-enxertos cítricos produzidos em diferentes substratos, no interior da casa de vegetação. EEA/UFRGS, Eldorado do Sul, 2003/2004.

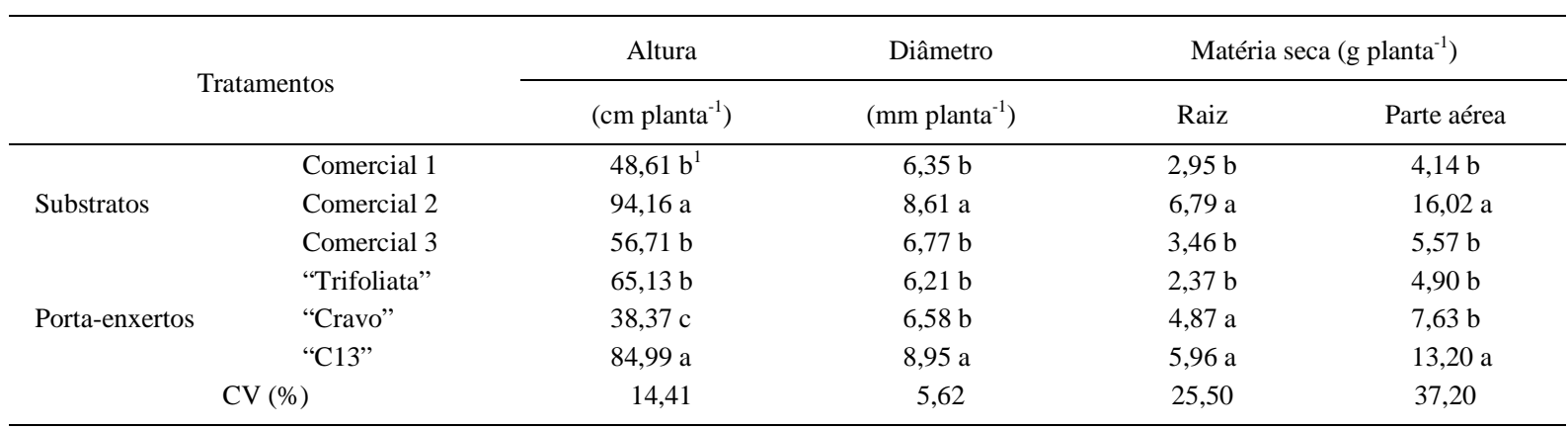

${ }^{1}$ Médias não seguidas por mesma letra na coluna diferem entre si pelo teste de Tukey, em nível de 5\% de probabilidade de erro.

Ciência Rural, v.37, n.4, jul-ago, 2007. 
de irrigações durante o dia, em menores intervalos, atrelado ao fornecimento de uma nutrição mais concentrada na fertirrigação.

Os porta-enxertos citrangeiro "C13" e limoeiro "Cravo” apresentaram semelhantes acúmulos de matéria seca nas raízes, que foram superiores ao “Trifoliata” (Tabela 3). Na parte aérea, o porta-enxerto citrangeiro "C13" foi superior aos demais, que não diferiram entre si. No total (raízes + parte aérea), o portaenxerto citrangeiro “C13” apresentou maior quantidade de matéria seca, seguido pelo limoeiro "Cravo" e "Trifoliata”, como conseqüência do ocorrido na parte aérea. No geral, o “Trifoliata” teve o menor acúmulo de matéria seca, devido às menores temperaturas decorridas no início do experimento e na primavera (Figura 1). A menor matéria seca apresentada pelo “Trifoliata” é explicada por tratar-se de um porta-enxerto menos vigoroso e de caráter caducifólio, que, como resposta às temperaturas amenas ocorridas na primavera (Figura 1), reduz sua atividade metabólica e retarda o seu desenvolvimento vegetativo (LEITE JUNIOR, 1992; OLIVEIRA et al., 2001).

Os resultados referentes aos teores de macronutrientes presentes na matéria seca das folhas dos porta-enxertos estão representados na tabela 4. A análise estatística somente revelou o efeito simples dos substratos e dos porta-enxertos. Apesar do maior aporte de nutrientes no substrato Comercial 2, antes do experimento (Tabela 1), não houve diferenças significativas nos teores foliares de nitrogênio, fósforo e potássio presentes nos porta-enxertos nos três substratos em estudo. Os teores de Cálcio foram maiores no substrato Comercial 1, e semelhantes nos demais. Os teores de Magnésio, ao contrário, foram maiores no substrato Comercial 3, intermediários no Comercial 1 e inferiores no Comercial 2 (Tabela 4). Os resultados de conteúdo nutricional dos porta-enxertos demonstraram uma maior absorção de nitrogênio pelo porta-enxerto “Trifoliata”, em relação aos outros porta-enxertos (Tabela 4). A absorção de fósforo, cálcio e magnésio foi semelhante nos três porta-enxertos utilizados. O porta-enxerto limoeiro "Cravo" absorveu mais potássio, seguido pelo "C13”, enquanto o porta-enxerto “Trifoliata” teve uma menor resposta na absorção deste nutriente (Tabela 4). O mesmo comportamento foi obtido por SCHÄFER (2004) nas condições de viveiro, com uma maior absorção de potássio pelo limoeiro “Cravo”, seguido pelo "C13”, enquanto que o “Trifoliata” absorveu menos potássio.

Apesar dos níveis altos de cálcio nos substratos (Tabela 1), observa-se que o conteúdo de cálcio, em todos os tratamentos, foi insuficiente (Tabela 4). Isto se deve a um forte antagonismo entre K/Ca e $\mathrm{Mg} / \mathrm{Ca}$, ou seja, quando há altos teores de um dos elementos, provoca a inibição na absorção do outro (MALAVOLTA\& \&IOLANTE NETTO, 1989).

A exportação total de N, P, K, Ca, e Mg foi maior nas plantas cultivadas no substrato Comercial 2, em relação aos demais, os quais não diferiram entre si, exceto para o Mg, que foi menor no Comercial 1 (Tabela 4). O citrangeiro “ $\mathrm{C} 13$ ” exportou mais macronutrientes que os outros porta-enxertos (Tabela 4). $\mathrm{N}$ e Ca foram exportados em semelhante medida pelo "Trifoliata” e o limoeiro "Cravo". O "Trifoliata” exportou menos P, K e $\mathrm{Mg}$, com o limoeiro “Cravo” exportando quantidades intermediárias.

$\mathrm{Na}$ tabela 5, são apresentados os percentuais de plantas aptas à enxertia no final deste experimento (165 DAR). Desta forma, o substrato Comercial 2 possibilitou maior percentagem de plantas

Tabela 4 - Concentração de macronutrientes presentes na matéria seca das folhas e exportados pela matéria seca total dos porta-enxertos produzidos em diferentes substratos, no interior da casa de vegetação. EEA/UFRGS, Eldorado do Sul, $2003 / 2004$.

\begin{tabular}{|c|c|c|c|c|c|c|c|c|c|c|c|}
\hline \multirow{2}{*}{\multicolumn{2}{|c|}{ Tratamentos }} & \multicolumn{5}{|c|}{ Macronutrientes na matéria seca da folha ( $\left.\mathrm{g} \mathrm{kg}^{-1}\right)$} & \multicolumn{5}{|c|}{$\begin{array}{l}\text { Macronutrientes exportados pela matéria seca total } \\
\text { dos porta-enxertos (g) }\end{array}$} \\
\hline & & $\mathrm{N}^{1}$ & $\mathrm{P}^{2}$ & $\mathrm{~K}^{3}$ & $\mathrm{Ca}^{4}$ & $\mathrm{Mg}^{5}$ & Nexp. & Pexp. & Kexp & Caexp & Mgexp \\
\hline \multirow{3}{*}{ Substratos } & Comercial 1 & 26,50 & 1,59 & 19,21 & $21,01 \mathrm{a}$ & $3,31 \mathrm{~b}$ & $0,19 \mathrm{~b}$ & $0,01 \mathrm{~b}$ & $0,14 \mathrm{~b}$ & $0,15 \mathrm{~b}$ & 0,02 c \\
\hline & Comercial 2 & 25,49 & 1,92 & 19,49 & $16,46 \mathrm{~b}$ & $2,67 \mathrm{c}$ & $0,56 \mathrm{a}$ & $0,04 \mathrm{a}$ & 0,45 a & $0,38 \mathrm{a}$ & $0,06 \mathrm{a}$ \\
\hline & Comercial 3 & 25,01 & 1,89 & 19,10 & $16,74 \mathrm{~b}$ & $4,63 \mathrm{a}$ & $0,22 \mathrm{~b}$ & $0,02 \mathrm{~b}$ & $0,18 \mathrm{~b}$ & $0,15 \mathrm{~b}$ & $0,04 \mathrm{~b}$ \\
\hline \multirow{3}{*}{$\begin{array}{l}\text { Porta- } \\
\text { enxertos }\end{array}$} & “Trifoliata” & $28,27 a^{6}$ & 1,83 & $16,41 \mathrm{c}$ & 16,70 & 3,73 & $0,21 \mathrm{~b}$ & $0,01 \mathrm{c}$ & $0,12 \mathrm{~b}$ & $0,12 \mathrm{~b}$ & $0,02 \mathrm{c}$ \\
\hline & “Cravo” & 24,42 b & 1,72 & 21,56 a & 18,11 & 3,43 & $0,29 \mathrm{~b}$ & $0,02 \mathrm{~b}$ & $0,27 \mathrm{a}$ & $0,21 \mathrm{~b}$ & $0,04 \mathrm{~b}$ \\
\hline & “C13” & $24,31 \mathrm{~b}$ & 1,85 & $19,83 \mathrm{~b}$ & 19,41 & 3,45 & $0,46 \mathrm{a}$ & 0,03 a & 0,37 a & $0,36 \mathrm{a}$ & $0,06 \mathrm{a}$ \\
\hline CV (\%) & & 9,04 & 16,16 & 6,19 & 13,07 & 10,04 & 31,85 & 28,62 & 34,71 & 39,59 & 29,55 \\
\hline
\end{tabular}

${ }^{1}$ Nitrogênio, ${ }^{2}$ Fósforo, ${ }^{3}$ Potássio, ${ }^{4}$ Cálcio, ${ }^{5}$ Magnésio, ${ }^{6}$ Médias não seguidas por mesma letra na coluna, em cada fator, diferem entre si pelo teste de Tukey, em nível de $5 \%$ de probabilidade de erro. 
Tabela 5 - Percentagem de porta-enxertos aptos à enxertia, produzidos em recipientes com diferentes substratos comerciais, no interior da casa de vegetação. EEA/UFRGS, Eldorado do Sul, 2003/2004.

\begin{tabular}{lccc}
\hline & \multicolumn{3}{c}{ Plantas aptas à enxertia (\%) } \\
\cline { 2 - 4 } Substratos & \multicolumn{3}{c}{ Porta-enxertos } \\
\cline { 2 - 4 } & “Trifoliata” & “Cravo” & “C13” \\
\hline Comercial 1 & $16,6 \mathrm{Bb}^{1}$ & $10,4 \mathrm{Bb}$ & $62,5 \mathrm{Ab}$ \\
Comercial 2 & $68,7 \mathrm{Ba}$ & $91,7 \mathrm{Aa}$ & $100,0 \mathrm{Aa}$ \\
Comercial 3 & $14,6 \mathrm{Bb}$ & $20,8 \mathrm{Bb}$ & $75,0 \mathrm{Ab}$ \\
CV (\%) & & 24,58 & \\
\hline
\end{tabular}

${ }^{1}$ Médias não seguidas por mesma letra, maiúscula na linha e minúscula na coluna, diferem entre si pelo teste de Tukey em nível de 5\% de probabilidade de erro.

aptas à enxertia, especialmente quando foram utilizados os porta-enxertos citrangeiro “C13” (100\% das plantas) e o limoeiro "Cravo" (92\% das plantas).

O melhor desempenho do substrato Comercial 2 deveu-se ao maior aporte de nutrientes presente na fase inicial do trabalho (Tabela 1), o que possibilitou maior exportação de nutrientes na matéria seca total dos porta-enxertos (Tabela 4), atrelado com o manejo utilizado da irrigação, pois induziu aos portaenxertos maior crescimento em altura, diâmetro, área foliar, número de folhas, área foliar por folha e matéria seca total.

O porta-enxerto citrangeiro “C13”, além de apresentar um ótimo desempenho quando produzido no substrato Comercial 2 (Tabela 5), sobressaiu-se aos demais porta-enxertos quando produzidos no substrato Comercial 1 (62\% das plantas) e Comercial 3 (75\% das plantas). Provavelmente, isso se deveu à, melhor captação e utilização dos nutrientes, convertendo-se em crescimento vegetativo (Tabela 4). Em condições de sementeira, SCHÄFER (2004) também verificou que o porta-enxerto citrangeiro "C13" apresenta um crescimento vegetativo igual ou superior aos portaenxertos limoeiro “Cravo” e “Trifoliata”.

\section{CONCLUSÕES}

O substrato influencia o desenvolvimento vegetativo dos porta-enxertos cítricos produzidos em recipientes. O substrato Comercial 2 possibilita maior desenvolvimento vegetativo aos porta-enxertos utilizados. O porta-enxerto citrangeiro “C13” apresenta grande desenvolvimento vegetativo, sendo uma alternativa para a diversificação de porta-enxertos para a citricultura.

\section{REFERÊNCIAS}

BELLÉ, S.; KÄMPF, A.N. Utilização de casca de arroz carbonizada como condicionador hortícola para um solo orgânico. Pesquisa Agropecuária Brasileira, Brasília, v.29, n.8, p.1265-1271, 1994.

BERGAMASCHI, H. et al. Clima da Estação Experimental da UFRGS (e Região de Abrangência). Porto Alegre: Universidade Federal do Rio Grande do Sul, 2004. 78p.

FERMINO, M.H. Aproveitamento de resíduos industriais e agrícolas como alternativas de substratos hortícolas. 1996. 90f. Dissertação (Mestrado em Fitotecnia) - Curso em Pós-graduação em Fitotecnia, Universidade Federal do Rio Grande do Sul.

FUNDECITRUS. Doenças e pragas. Acesso em 15 nov. 2004. Online. Disponível na Internet: http//www.fundecitrus. com.br/doencas/morte-subita.html.

KOLLER, O.C. Citricultura: laranja, limão e tangerina. Porto Alegre: Rígel, 1994. 446p. il.

LEITE JUNIOR, R.P. Cultivares de copa e porta-enxertos. In: IAPAR. A citricultura no Paraná. Londrina: Instituto Agronômico do Paraná, 1992. p.91-116 (Circular, 72).

MALAVOLTA, E.; VIOLANTE NETTO, A. Nutrição mineral, calagem, gessagem e adubação dos citros. Piracicaba: Associação Brasileira para Pesquisa da Potassa e do Fosfato, 1989. 153p.

OLIVEIRA, R.P. de. et al. Mudas de citros. Pelotas: Embrapa de Clima Temperado, 2001. 32p. (Sistemas de produção, 1).

SCHÄFER, G. Caracterização molecular, diagnóstico e avaliação de porta-enxertos na citricultura gaúcha. 2000. 81f. Dissertação (Mestrado em Fitotecnia) - Curso em Pósgraduação em Fitotecnia, Universidade Federal do Rio Grande do Sul.

SCHÄFER, G. Produção de porta-enxertos cítricos em recipientes e ambiente protegido no Rio Grande do Sul. 2004. 129f. Tese (Doutorado em Fitotecnia) - Curso em Pósgraduação em Fitotecnia, Universidade Federal do Rio Grande do Sul.

SCHMITZ, J.A.K. Cultivo de Poncirus trifoliata (L.) Raf. em recipientes: influência de substratos e de fungos micorrízicos arbusculares. 1998. 144f. Dissertação (Mestrado em Fitotecnia) - Curso em Pós-graduação em Fitotecnia, Universidade Federal do Rio Grande do Sul.

TEDESCO, M.J. et al. Análise de solo, plantas e outros materiais. 2.ed. Porto Alegre: Departamento de Solos da UFRGS, 1995. 174p. 